\title{
Mixed-metal $\mathrm{Cu}-\mathrm{Zn}$ thiocyanate coordination polymers with melting behavior, glass transition, and tunable electronic properties
}

Chayanit Wechwithayakhlung, ${ }^{\text {ab }}$ Suttipong Wannapaiboon, ${ }^{c}$ Sutassana Na-Phattalung, ${ }^{\text {de }}$

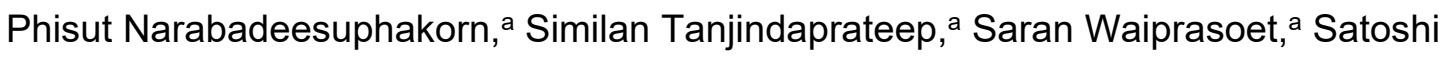
Horike, ${ }^{\star a b}$ and Pichaya Pattanasattayavong ${ }^{\star a f}$

\footnotetext{
a Department of Materials Science and Engineering, School of Molecular Science and Engineering, Vidyasirimedhi Institute of Science and Technology (VISTEC), Rayong, 21210, Thailand

b Institute for Integrated Cell-Material Sciences (iCeMS), Kyoto University, Kyoto 606-8501, Japan

c Synchrotron Light Research Institute (Public Organization), 111 University Avenue, Muang District, Nakhon Ratchasima, 30000, Thailand
}

${ }^{d}$ Division of Physics, School of Science, Walailak University, Nakhon Si Thammarat, 80160, Thailand

e Functional Materials and Nanotechnology Center of Excellence, Walailak University, Nakhon Si Thammarat, 80160, Thailand

${ }^{\mathrm{f}}$ Research Network of NANOTEC-VISTEC on Nanotechnology for Energy, Vidyasirimedhi Institute of Science and Technology (VISTEC), Rayong, 21210, Thailand

*Corresponding authors. Email: pichaya.p@vistec.ac.th, horike@icems.kyoto-u.ac.jp

\section{Abstract}

The solid-state mechanochemical reactions under ambient conditions of CuSCN and $\mathrm{Zn}(\mathrm{SCN})_{2}$ resulted in two novel materials: partially $\mathrm{Zn}$-substituted $\alpha$-CuSCN and a new phase $\mathrm{Cu}_{x} \mathrm{Zn}_{\mathrm{y}}(\mathrm{SCN})_{x+2 y}$. The reactions take place at the labile S-terminal, and both products show melting and glass transition behaviors. The optical band gap and solid-state ionization potential can be adjusted systematically by adjusting the $\mathrm{Cu}: \mathrm{Zn}$ ratio. Density functional theory calculations also reveal that the $\mathrm{Zn}$-substituted CuSCN structure features a complementary electronic structure of $\mathrm{Cu} 3 d$ states at the valence band maximum (VBM) and $\mathrm{Zn} 4 s$ states at 
the conduction band minimum (CBM). This work shows a new route to develop semiconductors based on coordination polymers which are becoming technologically relevant for electronic and optoelectronic applications.

Keywords: coordination polymers, semiconductors, mechanochemical reactions, electronic structures

\section{Introduction}

The ambidentate thiocyanate $\left(\mathrm{SCN}^{-}\right)$ligand can coordinate with either hard or soft metal atoms and serve as either a bridging or terminal ligand. ${ }^{1-3}$ Once studied mostly for structural coordination chemistry, the applications of metal thiocyanates (MSCN) in electronic and optoelectronic devices are emerging rapidly. For example, the thiocyanate $\left(\mathrm{SCN}^{-}\right)$ligand was employed for the electronic properties tuning of the light-absorbing molecules in dyesensitized solar cells (DSCs), of which SCN-bonded Ru dyes became the key players. ${ }^{4-7}$ More recently, copper(I) thiocyanate (CUSCN) has proved to be one of the highly promising transparent hole-transporting semiconductors, exhibiting wide-ranging applications in thin-film transistors (TFTs), ${ }^{8,9}$ organic light-emitting diodes (OLEDs), ${ }^{10,11}$ and various types of solar cells: DSCs, ${ }^{12,13}$ extremely-thin absorber (ETA) solar cells, ${ }^{14,15}$ quantum dot-sensitized solar cells (QDSCs), ${ }^{16,17}$ organic photovoltaics (OPVs), ${ }^{18,19}$ and perovskite solar cells (PSCs). ${ }^{20-23}$

The key attributes of CuSCN are its optical transparency and hole-transporting ability ( $p$-type conductivity), resulting from the electronic structure comprising mainly $\mathrm{Cu}^{\prime} 3 d^{10}$ states hybridized with S $3 p$ at the valence band maximum (VBM) and high-energy $\mathrm{SCN}^{-} \pi^{*}$ states at the conduction band minimum (CBM) $\cdot{ }^{24,25}$ Compared to oxygen-bonded ligands, the improved energy matching between metal and sulfur atoms can provide efficient charge transport pathway in coordination polymers (CPs); ${ }^{26-28}$ indeed the structure of CuSCN can be visualized as $2 \mathrm{D} \mathrm{Cu}-\mathrm{S}$ sheets connected via $\mathrm{CN}$ bridges. Furthermore, we recently showed that tin(II) thiocyanate $\left[\mathrm{Sn}(\mathrm{SCN})_{2}\right]$ is another transparent CP-based semiconductor with the VBM 
dominated by $S 3 p$ and $N 2 p$ states with contributions from $S n^{\| \prime} 5 s^{2}$ lone pair electrons and can be used as an ultrathin anode interlayer in OPVs. ${ }^{29,30} \mathrm{Sn}(\mathrm{SCN})_{2}$ was also employed as a dopant in an electron transport layer that led to significant enhancements in OPV and PSC efficiencies. ${ }^{31}$ These examples clearly show that thiocyanate CPs have strong potential for electronic applications. Advances in the development of MSCN CPs can also contribute material design guidelines to the field of electrically conductive metal-organic frameworks (MOFs), ${ }^{32-34}$ which is a hot topic in the research community and has begun to move toward practical electronic applications. ${ }^{35-38}$

The electronic states of MSCN CPs can be adjusted systematically by changing the metal centers. One compound of particular interest is zinc(II) thiocyanate $\left[\mathrm{Zn}(\mathrm{SCN})_{2}\right]$ which exhibits an electronic structure complementary to that of CuSCN. In the triclinic $\mathrm{Zn}(\mathrm{SCN})_{2}$ structure, ${ }^{39}$ the empty $4 s$ states of $\mathrm{Zn}^{\prime \prime}$ form the $\mathrm{CBM}$ below $\mathrm{SCN}^{-} \pi^{*}$ states whereas the VBM features the ligand states only. ${ }^{40}$ The excellent electron-transporting properties ( $n$-type conductivity) of semiconducting oxides based on $\mathrm{Zn}$ or In are well-known and attributed to the spherical $s$ orbitals forming the CBM states. ${ }^{41,42}$ In fact, the combination of such an $n$-type oxide with a Cu'-based $p$-type semiconductor has only been demonstrated recently for highperformance electronic applications. ${ }^{43,44}$ An interesting question therefore arises: can we create mixed $\mathrm{Cu}-\mathrm{Zn}$ thiocyanate compounds that would combine $\mathrm{Cu}^{\prime} 3 d$ states at the VBM and $\mathrm{Zn}$ " $4 s$ states at the CBM? Such combination could potentially lead to the construction of various electronic devices, such as ambipolar transistors, ${ }^{45}$ complementary circuits, ${ }^{46}$ or $p-n$ junction devices, ${ }^{47}$ based on CP semiconductors.

Due to the structural versatility of the $\mathrm{SCN}^{-}$ligand, heterometallic or mixed-metal thiocyanate CPs have been reported. For example, current attention on perovskite structures have led to interest in novel thiocyanate analogues: perovskite $\mathrm{CsCd}(\mathrm{SCN})_{3},{ }^{48}$ double perovskite $\left(\mathrm{NH}_{4}\right)_{2} \mathrm{NiCd}(\mathrm{SCN})_{6},{ }^{49}$ and Prussian blue (A-site vacancy double perovskite) $\mathrm{M}^{\prime \prime \prime} \mathrm{Bi}(\mathrm{SCN})_{6}(\mathrm{M}=\mathrm{Fe}, \mathrm{Cr}, \mathrm{Sc}) \cdot{ }^{50}$ Importantly, there are specific examples that include $\mathrm{Zn}$ as bimetallic thiocyanate CPs of group 12 metals, such as $\mathrm{ZnCd}(\mathrm{SCN})_{4}$ and $\mathrm{ZnHg}(\mathrm{SCN})_{4}$, which 
have been explored for their non-linear optical properties. ${ }^{51-54}$ The two metal sites are both tetrahedrally coordinated but distinct: one site bonded to $4 \mathrm{~N}\left(\mathrm{MN}_{4}\right)$, the other to $4 \mathrm{~S}\left(\mathrm{MS}_{4}\right)$. In the triclinic structure of $\mathrm{Zn}(\mathrm{SCN})_{2},{ }^{39}$ there also exist two $\mathrm{Zn}$ coordination environments: $\mathrm{ZnN}_{4}$ and $\mathrm{ZnS}_{4}$ (depicted as part of Fig. 1). As $\mathrm{Cu}^{\prime}$ also has a tetrahedral geometry and can coordinate via both $\mathrm{S}$ and $\mathrm{N}$, our motivation is therefore to explore the possibility of creating mixed Cu-Zn MSCN CPs that would yield electronic states from the metal centers at both VBM and CBM from $\mathrm{Cu}^{\prime} 3 d$ and $\mathrm{Zn}^{\prime \prime} 4 s$, respectively. To the best of our knowledge, such compounds have not been reported, and their discovery could open up a new compositional and/or structural space for further development of thiocyanate-based CP semiconductors.

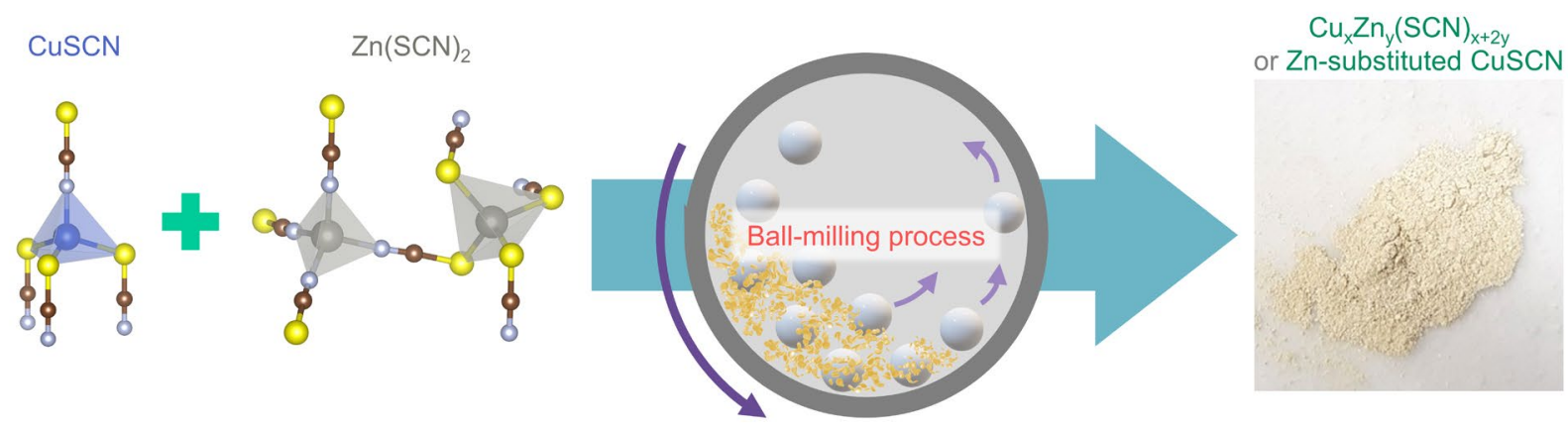

Fig. 1 Schematic diagram showing the combination of $\mathrm{CuSCN}$ and $\mathrm{Zn}(\mathrm{SCN})_{2}$ by a mechanochemical method to obtain $\mathrm{Cu}_{x} Z \mathrm{n}_{y}(\mathrm{SCN})_{x+2 y}$ and partially $\mathrm{Zn}$-substituted CuSCN.

Herein, we employed a solid-state mechanochemical method to combine CuSCN and $\mathrm{Zn}(\mathrm{SCN})_{2}$ at various mixing ratios and obtained a new bimetallic $\mathrm{Cu}_{x} \mathrm{Zn} \mathrm{n}_{\mathrm{y}}(\mathrm{SCN})_{\mathrm{x}+2 y}$ phase as well as (partially) Zn-substituted CuSCN for the first time (Fig. 1). The mechanochemical synthesis is a solvent-free reaction, allowing a direct combination of cations in SCN-based frameworks of which conventional solution synthesis cannot obtain. ${ }^{55}$ The optical properties and electronic levels of the mixed compounds can be systematically tuned by varying the $\mathrm{Cu} Z \mathrm{Zn}$ ratio. Remarkably, the products also display melting and glass transition behaviors; the 
liquid and glassy states of CPs are gaining immense research interest in recent years. ${ }^{56-58} \mathrm{We}$ also employed density functional theory to study the electronic properties of the partially Znsubstituted CuSCN and found that the complementary electronic structure of Cu $3 d$ VBM and Zn 4s CBM can be realized.

\section{Structural and thermal analyses}

The methods section is included in the Supplementary Information. Prior to reacting CuSCN and $\mathrm{Zn}(\mathrm{SCN})_{2}$ together, each of the precursors was ball-milled separately to see the effects of mechanical grinding on their crystal structures. The powder X-ray diffraction (PXRD) results of the ball-milled precursors, denoted as BM-Cu for CuSCN and BM-Zn for $\mathrm{Zn}(\mathrm{SCN})_{2}$, are included in Fig. 2a, which shows that their crystallinity can be broken down as seen from the broader XRD patterns. For CuSCN, the structure was also transformed from the rhombohedral (3R) $\beta$-phase (ICSD 24372) $)^{59}$ to the orthorhombic $\alpha$-phase (ICSD 124) $)^{60}$ following the grinding step (Fig. S1a, Supplementary Information). Consequently, the mechanochemical reactions of CuSCN and $\mathrm{Zn}(\mathrm{SCN})_{2}$ were carried out for different $\mathrm{Cu}(\mathrm{x}): \mathrm{Zn}(\mathrm{y})$ atomic ratios. The products, designated as $\mathbf{C} \mathbf{u}_{\mathbf{x}} \mathbf{Z} \mathbf{n}_{\mathbf{y}}$, appear as fine pale-yellow powder, which is different from the separately ball-milled precursors; $\mathrm{BM}-\mathrm{Cu}$ appears light gray whereas $\mathrm{BM}-\mathrm{Zn}$ appears pale pink. At an optimum ratio of 2:1 $\left(\mathbf{C u}_{2} \mathbf{Z} \mathbf{n}_{1}\right)$, all starting materials were completely converted into the product as evident from the absence of PXRD signals of the pristine precursors (discussed below), suggesting good reactivity of $\mathrm{CuSCN}$ and $\mathrm{Zn}(\mathrm{SCN})_{2}$. 


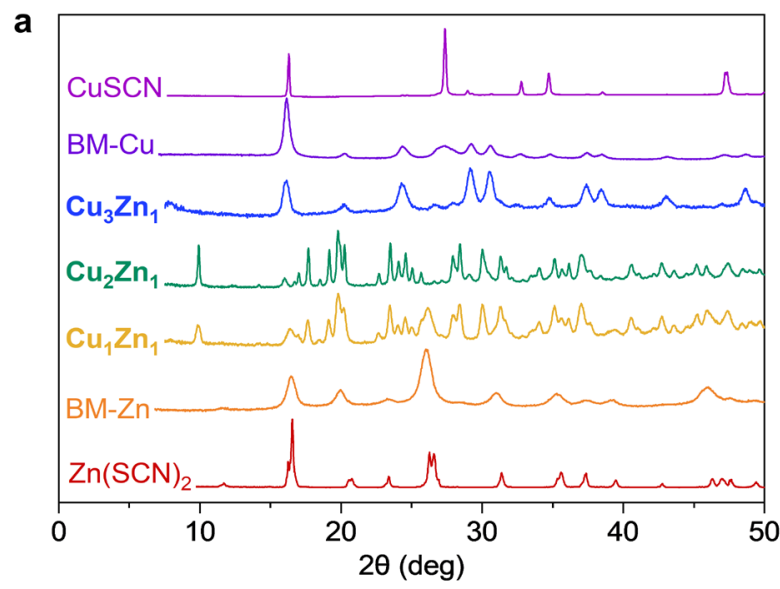

b

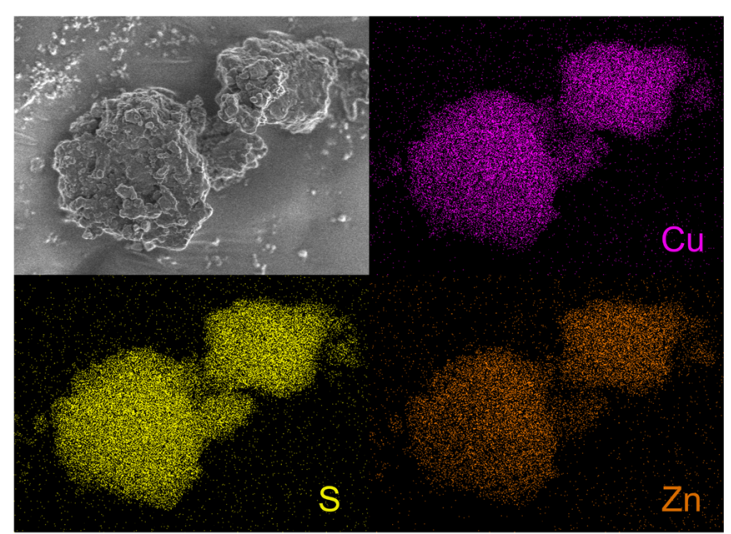

c

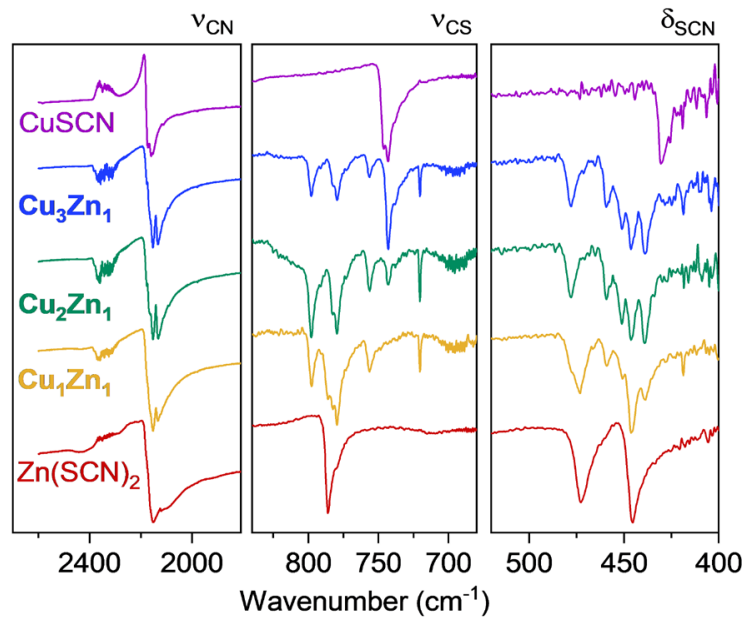

Fig. 2 (a) PXRD data of CuSCN and $\mathrm{Zn}(\mathrm{SCN})_{2}$ precursors, their ball-milled powders (BM-Cu and BM$\mathrm{Zn}$, respectively), and $\mathrm{Cu}_{\mathbf{x}} \mathrm{Zn}_{\mathrm{y}}$ products where $\mathrm{x}: \mathrm{y}$ is the $\mathrm{Cu}: \mathrm{Zn}$ atomic ratio. (b) SEM image and EDX analysis of $\mathbf{C u}_{2} \mathbf{Z} \mathbf{n}_{1}$ sample. (c) FTIR spectra.

The structural properties of the products were studied by PXRD as shown in Fig. $2 a$. We note that in addition to $3: 1,2: 1$, and $1: 1$ ratios displayed in the figure, other ratios with 
higher Cu proportion (5.79:1) or higher Zn proportion (1:2 and 1:3) were also attempted, and the results are included in Fig. S1b. For Cu-rich samples where $x: y \geq 3: 1\left(\mathbf{C u}_{3} \mathbf{Z} \mathbf{n}_{1}\right.$ and $\left.\mathrm{Cu}_{5.79} \mathbf{Z n}_{1}\right)$, the PXRD data can be identified as the $\alpha$-CuSCN phase without any detectable signals of $\mathrm{Zn}(\mathrm{SCN})_{2}$. The preferred crystalline orientation changes from (200)-dominant in BM$\mathrm{Cu}$ to (121)- and (112)-oriented in the mixed samples. This may suggest that mixing with $\mathrm{Zn}$ can disrupt the ordering along the longitudinal direction of the $\mathrm{SCN}^{-}$ligand (a-axis) which is more directional compared to the M-S network in the bc-plane (Fig. S1b, inset). On the other hand, for $\mathbf{C u}_{2} \mathbf{Z} \mathbf{n}_{1}$ sample, the PXRD result shows a distinct diffraction pattern which is indicative of a new phase, labelled as the copper-zinc thiocyanate (CZT) structure. The larger number of diffraction peaks may imply the alteration of crystal packing to a space group possessing a lower symmetry. When the proportion of $\mathrm{Zn}$ was increased further $\left(\mathbf{C u}_{1} \mathbf{Z} \mathbf{n}_{1}\right.$, $\mathrm{Cu}_{1} \mathbf{Z n}_{2}$, and $\left.\mathrm{Cu}_{1} \mathbf{Z n}_{3}\right)$, some PXRD signals of $\mathrm{Zn}(\mathrm{SCN})_{2}$ precursor can also be detected, suggesting the co-existence of $\mathrm{CZT}$ and $\mathrm{Zn}(\mathrm{SCN})_{2}$ structures. Furthermore, $\mathrm{Cu}_{5.79} \mathbf{Z n}_{1}$, as an example of a sample with the $\alpha$-CuSCN structure, was exposed to $85 \%$ relative humidity at 80 ${ }^{\circ} \mathrm{C}$ for $3 \mathrm{~h}$ and was found to convert to a mixture of CZT structure and $\alpha$-CuSCN as shown in Fig. S1c. The PXRD intensity of the CZT structure was also observed to increase following the water vapor exposure.

By examining $\mathrm{Cu}_{\mathbf{2}} \mathbf{Z} \mathbf{n}_{1}$ sample (CZT structure) with a scanning electron microscope (SEM), we observe that it consists of irregular-shaped particles with a broad size distribution (Fig. 2b). Energy-dispersive X-ray spectroscopy (EDX) shows homogeneous distributions of $\mathrm{Cu}, \mathrm{Zn}$, and $\mathrm{S}$ elements (also Fig. 2b), confirming that CZT is not a mixture and should be categorized as a new phase. Table $\mathrm{S} 1$ lists the atomic ratios of $\mathrm{Cu}, \mathrm{Zn}$, and $\mathrm{S}$ obtained from the EDX measurements. To compare with the nominal ratios from the synthesis, the data are normalized to the expected $\mathrm{Cu}$ atomic fraction. The trend in the ratios of $\mathrm{Zn}$ and $\mathrm{S}$ changes according to the expectation, but their values are lower than the nominal values. $\mathrm{Zn}$ is found to be $10-20 \%$ less than expected, possibly due to the overlap of $\mathrm{Cu}$ and $\mathrm{Zn} \mathrm{L}_{\alpha} \mathrm{X}$-ray emissions leading to experimental errors. $S$ is found to be consistently $30-40 \%$ lower than expected, 
likely due to the loss of sulfur from sublimation in high vacuum during the measurements. ${ }^{61}$ Fig. 2c displays the Fourier-transform infrared spectroscopy (FTIR) spectra of $\mathbf{C u}_{\mathbf{x}} \mathbf{Z} \mathbf{n}_{\mathbf{y}}$ samples in the relevant spectral ranges of CN stretching $\left(v_{\mathrm{CN}}, 2000-2200 \mathrm{~cm}^{-1}\right)$, CS stretching $\left(v_{\mathrm{CS}}\right.$, $\left.700-825 \mathrm{~cm}^{-1}\right)$, and SCN bending $\left(\delta_{\mathrm{SCN}}, 400-500 \mathrm{~cm}^{-1}\right) \cdot{ }^{62,63} v_{\mathrm{CN}}$ mode remains qualitatively similar for all samples whereas $v_{\mathrm{CS}}$ displays drastic changes, indicating that the S-terminal of $\mathrm{SCN}^{-}$is likely more labile which allows the solid-state reaction to take place. Peak splittings in the $v_{\mathrm{CS}}$ and $\delta_{\mathrm{SCN}}$ spectral ranges of $\mathbf{C u}_{\mathrm{x}} \mathbf{Z} \mathbf{n}_{\mathrm{y}}$ products are also evident, which could be related to the $\mathrm{SCN}^{-}$coordinating with two different metal cations. The results confirm that the $\mathrm{SCN}^{-}$ are intact and that new bonding environments are formed due to the mechanochemical reaction of CuSCN and $\mathrm{Zn}(\mathrm{SCN})_{2}$.
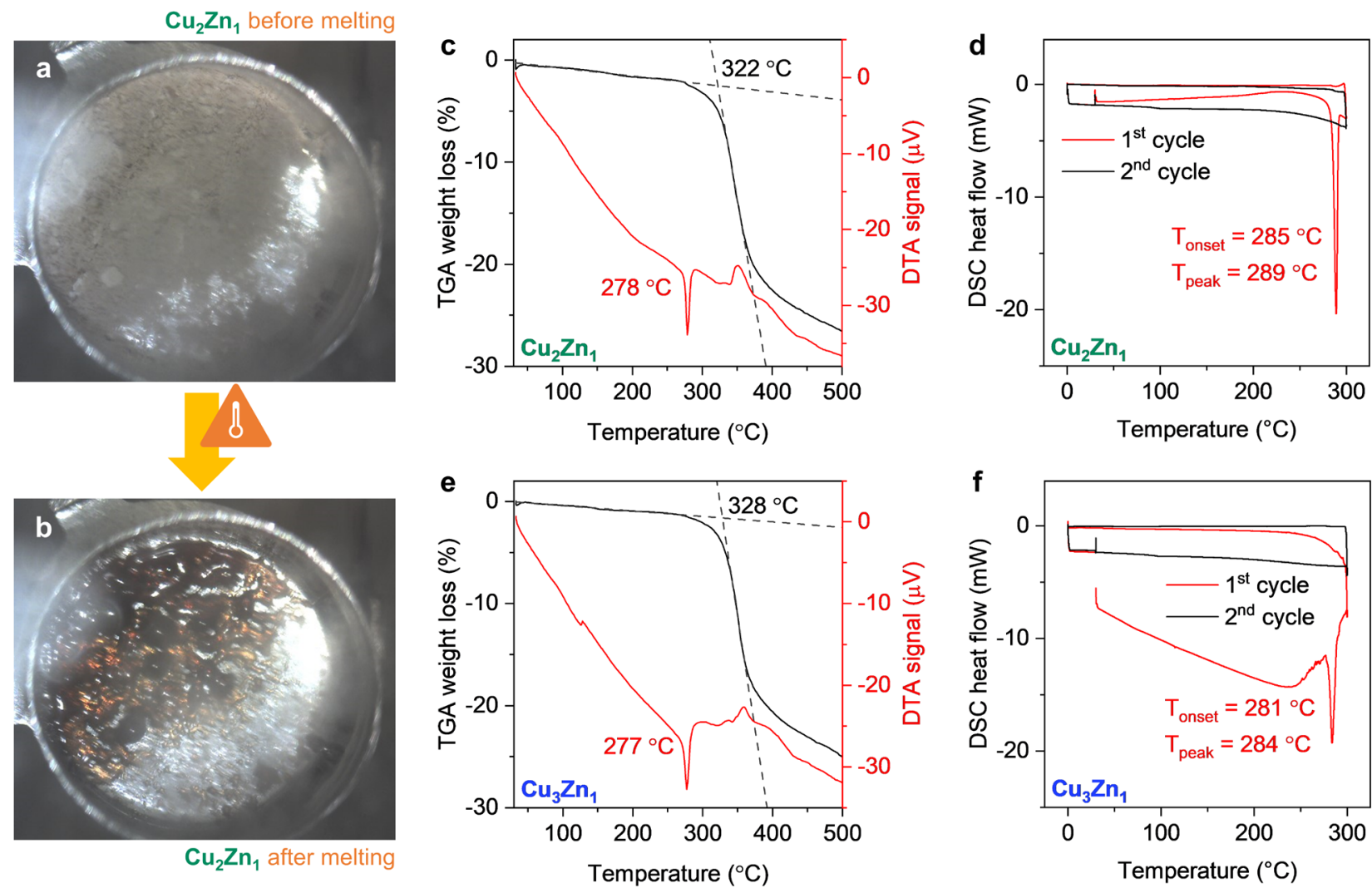

Fig. $3(a, b)$ Photographs of $\mathbf{C u}_{2} \mathbf{Z} \mathbf{n}_{1}$ sample before and after melting, taken during the TG-DTA measurement. (c, d) TG-DTA and DSC results of $\mathrm{Cu}_{2} \mathbf{Z} \mathbf{n}_{1}$ sample. (e, f) TG-DTA and DSC results of $\mathrm{Cu}_{3} \mathrm{Zn}_{1}$ sample. 
Considering the thermal properties, the parent compounds CuSCN and $\mathrm{Zn}(\mathrm{SCN})_{2}$ decompose at 408 and $393{ }^{\circ} \mathrm{C}$, respectively, as seen from the thermogravimetry-differential thermal analysis (TG-DTA) results (Fig. S2a-b). Interestingly, $\mathrm{Zn}(\mathrm{SCN})_{2}$ shows melting behavior, observed as an endothermic peak at $221{ }^{\circ} \mathrm{C}$ in Fig. S2b and visually in the photographs shown in Fig. S2c-d. The melting of $\mathrm{Zn}(\mathrm{SCN})_{2}$ has not been reported before, and its thermal characteristics suggest that the coordination bonds in $\mathrm{Zn}(\mathrm{SCN})_{2}$ can be broken more easily compared to CuSCN. In fact, many CPs that melt upon heating also consist of $\mathrm{Zn}^{11} .57,58$ When mixed together, $\mathbf{C u}_{\mathbf{x}} \mathbf{Z} \mathbf{n}_{\mathbf{y}}$ samples decompose at lower temperatures $\left(<330^{\circ} \mathrm{C}\right)$ and, remarkably, exhibit melting behavior in both Zn-mixed $\alpha$-CuSCN and CZT structures. The photographs before and after the melting of $\mathbf{C u}_{2} \mathbf{Z n}_{1}$ (CZT structure) are shown in Fig. 3a-b while the TG-DTA and differential scanning calorimetry (DSC) results are plotted in Fig. 3c-d, clearly displaying the melting behavior that occurs in the $280-290{ }^{\circ} \mathrm{C}$ range. For $\mathrm{Cu}_{1} \mathbf{Z n _ { 1 }}$ sample which contains mixed $\mathrm{CZT}$ and $\mathrm{Zn}(\mathrm{SCN})_{2}$ structures (see PXRD results in Fig. 2a), two melting instances are observed (Fig. S2e); the first one at $198^{\circ} \mathrm{C}$ is likely due to the coexisting $\mathrm{Zn}(\mathrm{SCN})_{2}$ phase whereas the second peak at $290{ }^{\circ} \mathrm{C}$ can be ascribed to the $\mathrm{CZT}$ phase. Similarly, the $\alpha$-CuSCN phase when containing $\mathrm{Zn}^{\|}$in the structure also exhibits melting behavior in the same temperature range as can be seen from the results of $\mathbf{C u}_{3} \mathbf{Z} \mathbf{n}_{1}$ shown in Fig. 3e-f. Even at a lower concentration of $\mathbf{Z n}\left(\mathbf{C u}_{5.79} \mathbf{Z n}_{1}\right)$, the melting still occurs (Fig. S2f), further emphasizing that $\mathrm{Zn}$ " can promote the solid-to-liquid phase transition. From the DSC experiments, the $\mathbf{C u}_{\mathbf{x}} \mathbf{Z} \mathbf{n}_{\mathbf{y}}$ products transform into an amorphous, glassy state following the first heating as evident from the occurrence of glass transition during the second heating around $90{ }^{\circ} \mathrm{C}$ as shown in Fig. S3. 

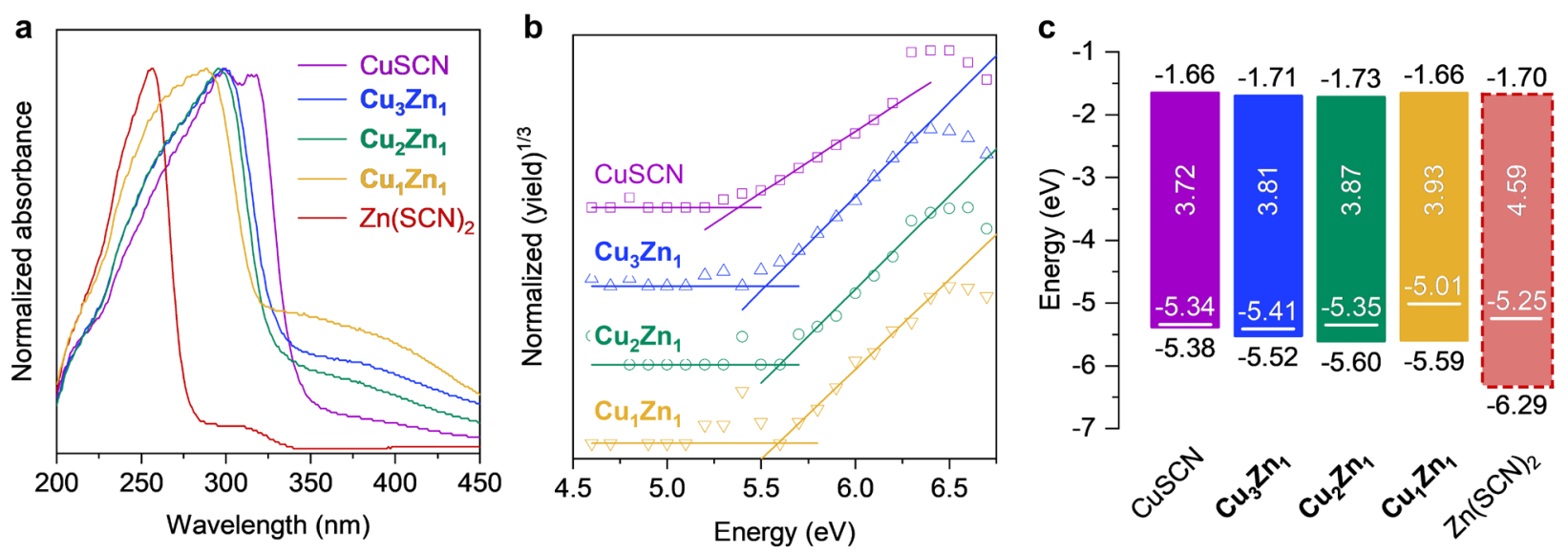

Fig. 4 (a) Optical absorbance spectra of powder samples. (b) Photoelectron yield ${ }^{1 / 3}$ spectra for the determination of the valence band edge. (c) Simple band diagrams showing the $E_{g}$ opt, VBM, CBM, and EF.

\section{Optical and electronic properties}

The optical properties of the samples were studied by diffuse reflectance spectroscopy. The optical absorption spectra were calculated from the reflection spectra using the Kubelka-Munk model as plotted in Fig. $4 \mathrm{a}$, and the optical band gaps $\left(E_{\mathrm{g}}{ }^{\mathrm{opt}}\right)$ were calculated from Tauc plots (Fig. S4). The main absorption peak is blue-shifted from $315 \mathrm{~nm}$ for CuSCN to $256 \mathrm{~nm}$ for $\mathrm{Zn}(\mathrm{SCN})_{2}$, accompanied by an increase of $E_{\mathrm{g}}{ }^{\text {opt }}$ with the increasing proportion of $\mathrm{Zn}$ from 3.72 $\mathrm{eV}$ for CuSCN to $4.59 \mathrm{eV}$ for $\mathrm{Zn}(\mathrm{SCN})_{2}$. The energetic positions of the VBM, i.e., the solidstate ionization potentials, were obtained from photoelectron yield spectroscopy (PYS) and found to descend deeper with respect to the vacuum level also with the increasing proportion of $\mathrm{Zn}$ as shown in Fig. 4b. The simplified energy band diagrams with data of $E_{\mathrm{g}}{ }^{\mathrm{opt}}$, VBM, CBM $\left(C B M=V B M+E_{g}^{o p t}\right)$, and Fermi level $\left(E_{F}\right.$, measured by Kelvin probe $)$ are shown in Fig. 4c. We note that the VBM of $\mathrm{Zn}(\mathrm{SCN})_{2}$ was out of range of our PYS instrument and could not be measured directly. However, the results from the other samples in Fig. 4c show that the CBM level does not vary significantly; this is likely due to electronic states in the conduction bands being dominated by the $\mathrm{SCN} \pi^{*}$ states which were present in all samples. This agrees with 
our previous theoretical study of $\mathrm{CuSCN}$ and $\mathrm{Zn}(\mathrm{SCN})_{2}$ (although there are $\mathrm{Zn}^{\text {"l }}$ states below the $\mathrm{SCN} \pi^{*}$ states in $\mathrm{Zn}(\mathrm{SCN})_{2}$, the density of states is significantly lower $) .{ }^{40} \mathrm{We}$ therefore reason that the CBM level of $\mathrm{Zn}(\mathrm{SCN})_{2}$ should be close to those of other samples around 1.70 $\mathrm{eV}$, and the VBM can be obtained from CBM $-E_{\mathrm{g}}{ }^{\text {opt }}$ in this case. The inclusion of $\mathrm{Zn}$ " also shifts $E_{F}$ away from the VBM, agreeing with the fact that $\mathrm{Zn}^{\|}$contributes $4 s$ states to the CBM (discussed in the section on computational study). The systematic shifts in the energy levels as a function of $\mathrm{Zn}$ proportion show that mixing with $\mathrm{Zn}(\mathrm{SCN})_{2}$ is one promising method to tune the electronic properties of CuSCN.

\section{Local environments of $\mathrm{Cu}$ and $\mathrm{Zn}$}

To investigate the local coordination environment, the samples were characterized by X-ray absorption spectroscopy (XAS) at beamline BL1.1W, Synchrotron Light Research Institute (SLRI), Thailand. The XAS spectra at Cu K-edge and Zn K-edge were recorded in both X-ray absorption near edge structure (XANES) and extended X-ray absorption fine structure (EXAFS) regions as shown in Fig. 5, and the analyzed EXAFS data in k-space and R-space are shown in Fig. S5. First, we observe that the ball-milling process does not alter the local $\mathrm{Cu}$ and $\mathrm{Zn}$ environments of pristine $\mathrm{CuSCN}$ and $\mathrm{Zn}(\mathrm{SCN})_{2}$. Specifically, the phase transition of $\mathrm{BM}-\mathrm{Cu}$ with respect to pristine $\mathrm{CuSCN}$ upon grinding leads to the alteration of crystal packing (change in XRD pattern) but does not alter the local structure of $\mathrm{Cu}$ (Fig. 5a and Fig. S5a-b). In the case of BM-Zn, both PXRD and XAS data are matched well with the pristine $\mathrm{Zn}(\mathrm{SCN})_{2}$ indicating that only the pulverization of bulk particles into smaller particles upon grinding occurred. Moreover, $\mathrm{Cu}$ and $\mathrm{Zn}$ are confirmed to be in +1 and +2 oxidation states, respectively, in all samples as evident from the XANES spectra. Upon ball-milling of the mixed metal precursors, the $\mathrm{Cu}$ K-edge EXAFS spectra of all samples with varying $\mathrm{Cu}: \mathrm{Zn}$ ratio appear similar to that of $\mathrm{BM}-\mathrm{Cu}$, indicating a similar local structure of $\mathrm{Cu}$. This observation suggests that there is no significant modification of the Cu local environment in CuSCN, BM$\mathrm{Cu}$, and $\mathbf{C u}_{\mathrm{x}} \mathbf{Z} \mathbf{n}_{\mathrm{y}}$ samples. 

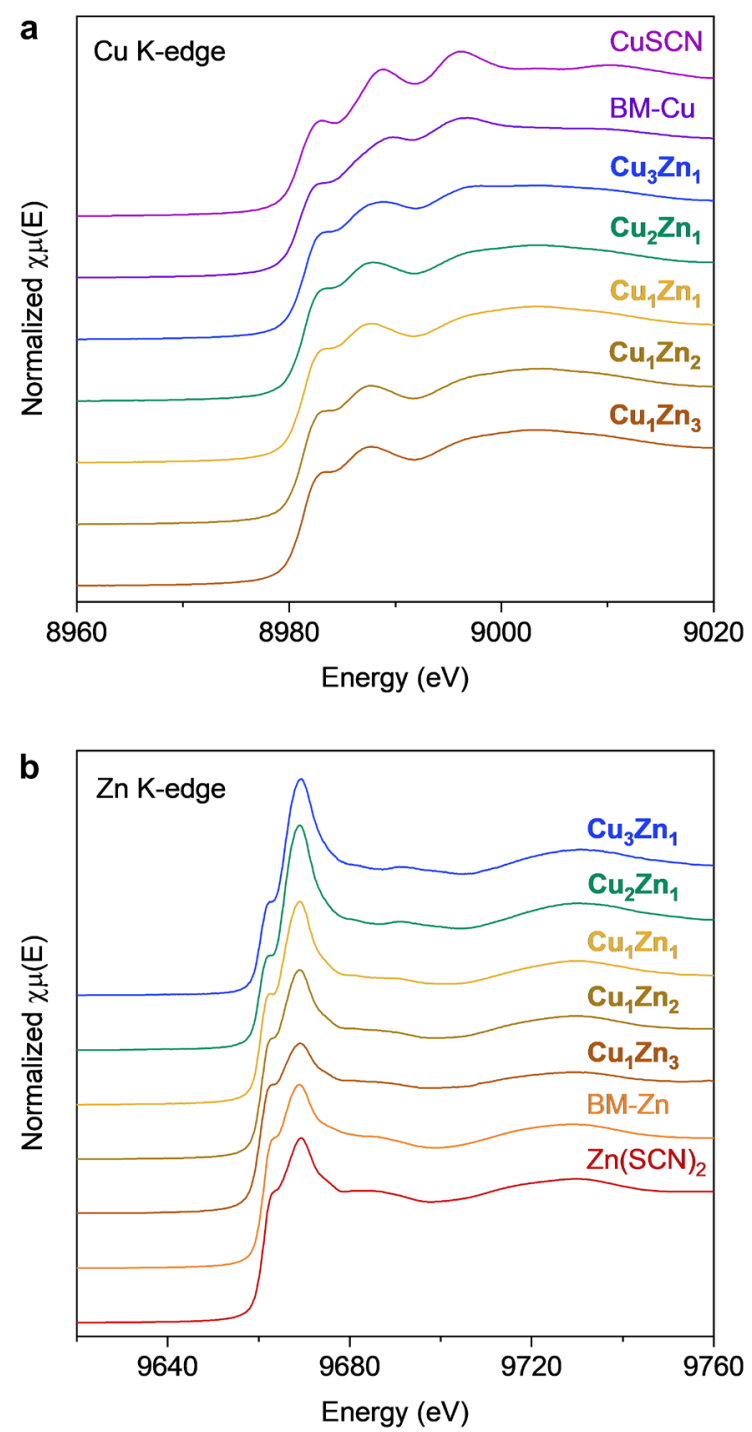

Fig. 5 XAS spectra at (a) Cu K-edge and (b) Zn K-edge in both XANES and EXAFS regions.

On the contrary, the $\mathrm{Zn} \mathrm{K}$-edge EXAFS spectra of the $\mathbf{C} \mathbf{u}_{\mathbf{x}} \mathbf{Z} \mathbf{n}_{\mathbf{y}}$ products vary with the x:y ratio (Fig. $5 b$ and Fig. S5c-d). The $\mathbf{Z n ~ K - e d g e ~ s p e c t r a ~ o f ~} \mathbf{C u}_{3} \mathbf{Z n}_{1}$ and $\mathbf{C u}_{2} \mathbf{Z} \mathbf{n}_{1}$ samples are similar to each other even though their PXRD patterns are different. In $\mathbf{C u}_{3} \mathbf{Z} \mathbf{n}_{1}$ which has the $\alpha$-CuSCN-based structure, $\mathrm{Zn}$ likely exists as a substitutional defect since the crystal ionic radii of $\mathrm{Cu}^{\prime}$ and $\mathrm{Zn}^{\prime \prime}$, both in the tetrahedral coordination geometry in thiocyanate compounds, are the same: $0.74 \AA .{ }^{64}$ Our computational study also confirms that the Zn-substitutional defect can form in $\alpha$-CuSCN as discussed in the next section. Although $\mathbf{C u}_{2} \mathbf{Z n}_{\mathbf{1}}$ has a crystal structure of the new CZT phase, the local $Z n$ environment is similar to that of $\mathbf{C u}_{3} \mathbf{Z n}_{1}$, characterized by 
two peaks approximately at 1.5 and $2.5 \AA$ in the R-space data (Fig. S5d). We also note the correspondence of FTIR spectra between the $\mathbf{C u}_{3} \mathbf{Z} \mathbf{n}_{1}$ and $\mathbf{C u}_{2} \mathbf{Z} \mathbf{n}_{1}$ samples as shown in Fig. 2c, further highlighting the similarity of the bonding environments in the two different crystal structures. This implies that the local environments in the CZT structure is possibly based on that of $\alpha$-CuSCN as well, but the crystal structure differs in terms of packing and symmetry. When the $\mathbf{Z n}$ atomic fraction increases $\left(\mathbf{C u}_{1} \mathbf{Z n}_{1}, \mathbf{C u}_{1} \mathbf{Z n}_{2}\right.$, and $\left.\mathbf{C u}_{1} \mathbf{Z n}_{3}\right)$, there is an additional peak at $2 \AA$ in the R-space data which coincides with the spectra of BM-Zn and $\mathrm{Zn}(\mathrm{SCN})_{2}$. This is in agreement with the PXRD data which show that these samples were mixtures of $\mathrm{CZT}$ and $\mathrm{Zn}(\mathrm{SCN})_{2}$ phases.

\section{Computational study of Zn-substituted $\alpha$-CuSCN}

Following the identification of the potential existence of Zn-substitutional defect at $\mathrm{Cu}$ sites $\left(\mathrm{Zn}_{\mathrm{Cu}}\right)$ in $\alpha$-CuSCN, we performed DFT calculations to study its formation energy and the effects on the electronic properties. The concentration $(C)$ of a defect $(D)$ under thermodynamic equilibrium can be determined by

$$
C\left(D^{q}\right)=\exp \left[-\frac{E^{f}\left(D^{q}\right)}{k_{B} T}\right]
$$

where $E^{f}\left(D^{q}\right)$ is the formation energy of defect $D$ in a charge state $q, k_{B}$ is the Boltzmann constant, and $T$ is the temperature. This equation shows the inverse relationship between the concentration of a defect and the defect formation energy. The latter is defined as ${ }^{65,66}$

$$
E^{f}=E_{t o t}\left(D^{q}\right)-E_{t o t}(0)+\sum \Delta n_{x} \mu_{x}+q E_{F}
$$

where $E_{\text {tot }}\left(D^{q}\right)$ is the total energy of the cell containing defect $D$ in a charge state $q, E_{\text {tot }}(0)$ is the total energy of bulk $\alpha$-CuSCN without any defects, $\Delta n_{x}$ is the number of an atom of species $X$ being removed (positive) or added (negative) to the cell, $\mu_{x}$ is the chemical potential of an atom of species $X$, and $E_{F}$ is the Fermi energy. In this study, the chemical potentials $\mu$ of $\mathrm{Cu}$ and $\mathrm{Zn}$ were set to the values of their natural phases, which are fcc $\mathrm{Cu}$ and hcp $\mathrm{Zn}$. It is worth 
noting that although the rough approximations of these chemical potentials are expected to be different from those obtained by determining alternative phases that are favorable under extreme growth conditions, these values are still useful as a first approximation to calculate the formation energy.

We performed the calculations for $\alpha$-CuSCN with one $\mathrm{Cu}$ position (out of eight $\mathrm{Cu}$ atoms in a unit cell) substituted with a $\mathrm{Zn}$ atom, so called a point defect. Two charge states of $q=0$ and $+1\left(\mathrm{Zn}_{\mathrm{Cu}}^{0}\right.$ and $\mathrm{Zn}_{\mathrm{Cu}}^{+}$, respectively) were found to be stable. We note that $\mathrm{Zn}_{\mathrm{Cu}}^{0}$ and $\mathrm{Zn}_{\mathrm{Cu}}^{+}$correspond to $\mathrm{Zn}$ in the oxidation states of $\mathrm{Zn}^{\prime}$ and $\mathrm{Zn}$ ", respectively. Specifically, if $\mathrm{Cu}^{\prime}$ is substituted with $\mathrm{Zn}^{\prime}$, the defect is in the neutral charge state; when $\mathrm{Cu}^{\prime}$ is substituted with $Z \mathrm{n}^{\prime \prime}$, the defect has a charge of +1 . The calculated formation energies as a function of $E_{\mathrm{F}}$ are shown in Fig. S6. In the plot, $E_{\mathrm{F}}$ is referenced to the VBM and varied from $0 \mathrm{eV}$ and $3.82 \mathrm{eV}$, which is the calculated band gap of $\alpha$-CuSCN from DFT employing the HSE06 hybrid exchange-correlation functional. The calculated band gap value agrees well with the experimental value found at $3.72 \mathrm{eV}$ (Fig. 4c), verifying that the calculations with the HSE06 functional provide a more accurate band gap value than those with typical DFT exchangecorrelation functionals, such as local density approximation (LDA) or generalized gradient approximation (GGA).

As seen in Fig. S6, the formation energy of $\mathrm{Zn}_{\mathrm{Cu}}^{+}$is lower than that of $\mathrm{Zn}_{\mathrm{Cu}}^{0}$ for most of the $E_{\mathrm{F}}$ range $\left(E_{\mathrm{F}}<3.04 \mathrm{eV}\right)$ and becomes negative for $E_{\mathrm{F}}<0.87 \mathrm{eV}$. This suggests that the formation of $\mathrm{Zn}_{\mathrm{Cu}}^{+}$is spontaneous when $\alpha$-CuSCN is under $p$-type condition which is the case for our samples as seen from the position of $E_{\mathrm{F}}$ being close to VBM (Fig. 4c). In addition, to verify the oxidation state of the $\mathrm{Zn}$ atom in the $\mathrm{Zn}_{\mathrm{Cu}}^{+}$defect, we carried out the Bader charge analysis ${ }^{67}$ and compared the Bader charge on $\mathrm{Zn}$ between $\mathrm{ZnO}$ and $\mathrm{Zn}_{\mathrm{Cu}}^{+}$. We find that the calculated Bader charge on $\mathrm{Zn}$ in $\mathrm{ZnO}$ is +1.15 whereas that on $\mathrm{Zn}$ in $\mathrm{Zn}_{\mathrm{Cu}}^{+}$is +1.03 ; the good agreement between the two cases suggest that they possibly have a similar oxidation state. As $\mathrm{Zn}$ in $\mathrm{ZnO}$ is known to be in the $\mathrm{Zn}^{\prime \prime}$ oxidation state, $\mathrm{Zn}$ in $\mathrm{Zn}_{\mathrm{Cu}}^{+}$is likely to be $\mathrm{Zn}^{\prime \prime}$ as well. The calculations results support that $\mathrm{Zn}^{\prime \prime}$ can substitute $\mathrm{Cu}^{\prime}$ in $\alpha$-CuSCN, forming $\mathrm{Zn}_{\mathrm{Cu}}^{+}$defects 
without incurring an energy penalty. On the other hand, $\mathrm{Zn}_{\mathrm{Cu}}^{0}$ can be more stable (when compared to $\mathrm{Zn}_{\mathrm{Cu}}^{+}$) only when $E_{\mathrm{F}}>3.04 \mathrm{eV}$, i.e., under $n$-type condition, which is not likely for CuSCN that is generally observed to display p-type conductivity. ${ }^{13,14,68}$ Therefore, $\mathrm{Zn}^{\prime}$ (which would give rise to $\mathrm{Zn}_{\mathrm{Cu}}^{0}$ ) is less likely to exist in our samples. The findings also corroborate well with the results from XANES measurements that show $\mathrm{Cu}$ and $\mathrm{Zn}$ exist as $\mathrm{Cu}^{\prime}$ and $\mathrm{Zn}$ " in all samples as discussed in the previous section.

To investigate the effects of $\mathrm{Zn}_{\mathrm{Cu}}^{+}$on the electronic structure of $\alpha$-CuSCN, charge densities at the highest occupied state and lowest unoccupied state (i.e., at the VBM and CBM, respectively) as well as the total density of states (DOS) and partial DOS (pDOS) were calculated for both bulk $\alpha$-CuSCN and $\alpha-\mathrm{CuSCN}$ with $\mathrm{Zn}_{\mathrm{Cu}}^{+}$. Comparing the charge densities of former (Fig. 6a-b) against those of the latter (Fig. 6c-d), the electronic states of substitutional $\mathrm{Zn}^{\prime \prime}$ are featured specifically at the CBM and not at all at the VBM. DOS and pDOS plotted in Fig. 6e also show that the VB of $\alpha$-CuSCN is minimally affected by the Zn-substitution and retains the $\mathrm{Cu} 3 d$-dominant character. In contrast, the $\mathrm{CB}$ shows defect-induced states derived from $\mathrm{Zn} 4 \mathrm{~s}$ states below the CBM. Importantly, $\mathrm{Zn}_{\mathrm{Cu}}^{+}$does not lead to any defect levels within the band gap that would otherwise act as deep trapping states. In fact, $\mathrm{Zn} 4 \mathrm{~s}$ is delocalized via the hybridization with $\mathrm{C}$ and $\mathrm{N} 2 p$ states, evident from the charge distribution over $\mathrm{Zn}, \mathrm{C}$, and $\mathrm{N}$ at the $\mathrm{CBM}$ as illustrated in Fig. $6 \mathrm{~d}$. Furthermore, $\mathrm{Zn}_{\mathrm{Cu}}^{+}$can be classified as an electron donor state due to its presence at the CBM. Each substitutional $\mathrm{Zn}^{\prime \prime}$ donates 1 extra electron (compared to $\mathrm{Cu}^{\prime}$ in the host lattice) to the conduction band of $\alpha$-CuSCN and simultaneously forms an ionized donor state with +1 charge, hence the charge neutrality is maintained. The electron donation is also reflected in the shift of $E_{\mathrm{F}}$ away from the VB edge of $\alpha$-CuSCN when $\mathrm{Zn}$ is added as observed in the experimental results (Fig. 4c). 

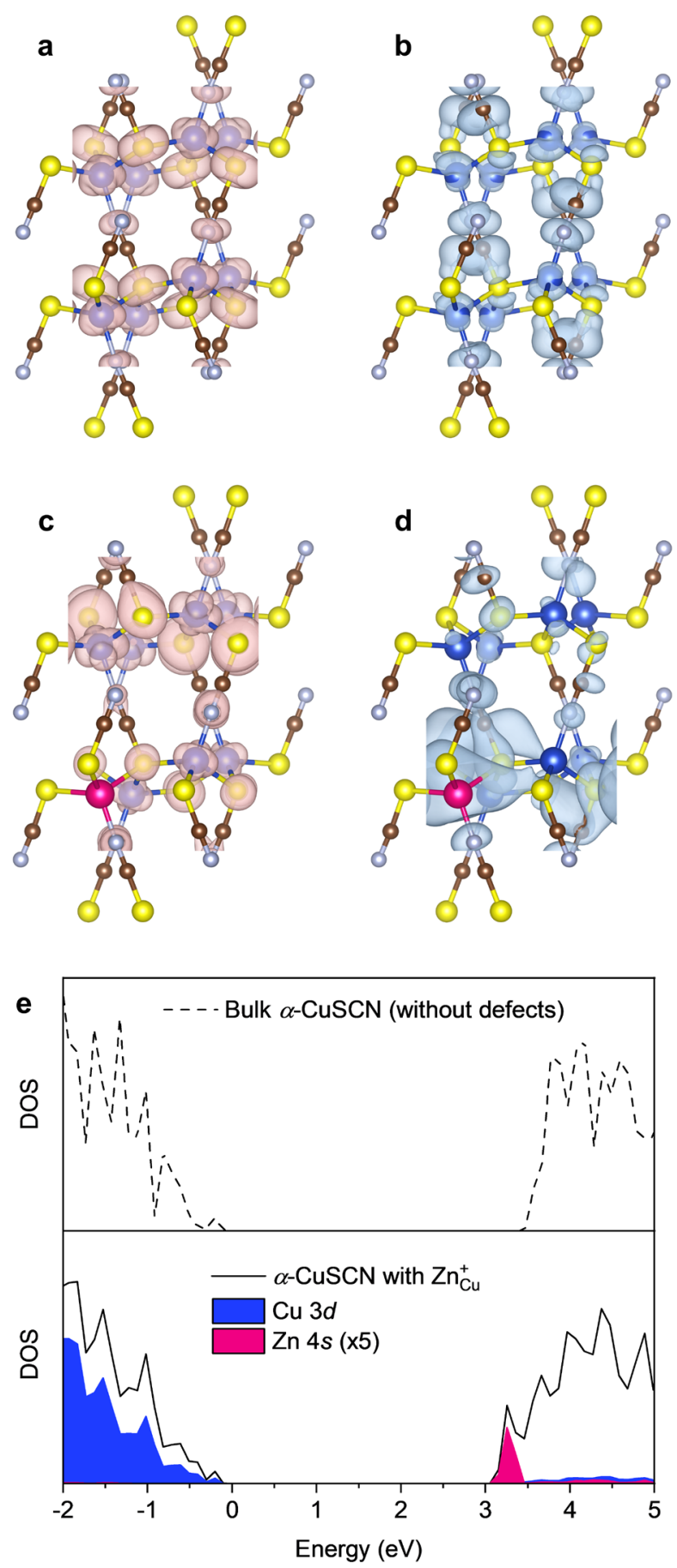

Fig. 6 Illustrations of charge densities of bulk $\alpha$-CuSCN (without defects) at (a) the highest occupied state and (b) the lowest unoccupied state in comparison with the charge densities of $\alpha$-CuSCN with $\mathrm{Zn}_{\mathrm{Cu}}^{+}$also at (c) the highest occupied state and (d) the lowest unoccupied state. The blue, pink, yellow, brown, and grey spheres refer to $\mathrm{Cu}, \mathrm{Zn}, \mathrm{S}, \mathrm{C}$, and $\mathrm{N}$, respectively. (e) Total and site-decomposed electron density of state (DOS), where the dashed and solid lines are the total DOS of bulk $\alpha$-CuSCN and of $\alpha$-CuSCN with $\mathrm{Zn}_{\mathrm{Cu}}^{+}$, respectively. The blue and pink shaded area are the partial DOS of $\mathrm{Cu} 3 d$ and $\mathrm{Zn} 4 s$ states, respectively. Note that the DOS on the $\mathrm{Zn}$ atom is scaled up by a factor of 5 for clarity. 


\section{Discussions}

Based on the results presented in this work, we surmise that during the mechanochemical reaction, the $\mathrm{Zn}(\mathrm{SCN})_{2}$ structure can be broken down (also evident from its melting behavior), after which $\mathrm{Zn}$ " can be incorporated into the $\alpha$-CuSCN structure which is more rigid. The similar crystal ionic radii and coordination geometry between $\mathrm{Cu}^{\prime}$ and $\mathrm{Zn}^{\prime \prime}$ allow the two metal ions to mix. When $\mathrm{Cu}$ is in excess $\left(\mathbf{C u}_{5.79} \mathbf{Z n}_{1}\right.$ and $\left.\mathbf{C u}_{3} \mathbf{Z n}_{1}\right)$, the main structure of $\alpha$-CuSCN is retained in which $Z n^{\|}$exists as a substitutional defect $\left(Z n_{C_{u}}\right)$. The computational study by DFT also finds that $Z n_{C u}$ in +1 charge state is stable with low formation energies especially when $E_{\mathrm{F}}$ is close to VBM ( $p$-type condition), which is the case for our samples. However, when the ratio is $2: 1\left(\mathbf{C u}_{2} \mathbf{Z} \mathbf{n}_{1}\right)$, the large number of defect sites likely increases the crystal energy such that the orthorhombic packing of $\alpha$-CuSCN is no longer stable, transforming into a low-symmetry space group - the CZT structure - with a nominal chemical formula of $\mathrm{Cu}_{2} \mathrm{Zn}(\mathrm{SCN})_{4}$. A further increase in the $\mathrm{Zn}$ atomic fraction results in the co-existence of $\mathrm{CZT}$ and $\mathrm{Zn}(\mathrm{SCN})_{2}$ structures, suggesting that the CZT phase may be at the boundary for homogeneous mixing between $\mathrm{Cu}^{\prime}$ and $\mathrm{Zn}^{\prime \prime}$ in the thiocyanate compound.

Importantly, the substitution of $\mathrm{Cu}^{\prime}$ with $\mathrm{Zn}^{\prime \prime}$ leads to the presence of $\mathrm{Zn}^{\prime \prime} 4 s$ orbitals at the CBM of $\alpha$-CuSCN, forming delocalized states via the hybridization with $\mathrm{C}$ and $\mathrm{N} 2 p$ states. As a result, $\mathrm{Zn}_{\mathrm{Cu}}^{+}$becomes a donor state that shifts $E_{\mathrm{F}}$ away from VBM toward midgap. With the top of the VB still formed mostly by $\mathrm{Cu}^{\prime} 3 d, \alpha$-CuSCN with $\mathrm{Zn}_{\mathrm{Cu}}^{+}$shows a novel electronic structure with metal-dominant character at both VBM and CBM. Mixing Cu/Zn in the thiocyanate compounds is shown as an effective method to systematically tune the optical and electronic properties. As CuSCN has been demonstrated as a highly promising semiconductor, this method could offer a novel route to fine-tuning the electronic levels, for example the VBM and $E_{F}$ levels, to match with the energy levels of other layers in thin-film electronic devices.

Another remarkable point is the observation of the melting behavior of $\mathbf{C} \mathbf{u}_{\mathbf{x}} \mathbf{Z} \mathbf{n}_{\mathbf{y}}$ products. Crystal melting of CPs is rare, ${ }^{56}$ and such behavior of CuSCN-based CPs has only 
recently been discovered. In the previous work, CuSCN was modified with 4,4'-bipyridin-1-ium derivatives to allow melting behavior. ${ }^{69}$ In our current system, the melting is realized by combining two metal cations with different oxidation states, $\mathrm{Cu}^{\prime}$ and $\mathrm{Zn}^{\prime \prime}$. As both are tetrahedrally coordinated with thiocyanate ligands, the charge difference may also affect electrostatic interactions and reduce lattice potential energies, leading to the emergence of melting behavior and glassy state. This would allow a novel solvent-free method for the deposition of CuSCN-based semiconductors. Further investigations should look at how much $\mathrm{Zn}$ doping is required to allow melting as well as characterize the electronic properties of meltprocessed CuSCN-based thin films.

\section{Conclusions}

Starting from CuSCN and $\mathrm{Zn}(\mathrm{SCN})_{2}$, we applied the mechanochemical synthesis method to successfully obtain new materials: (1) partially Zn-substituted $\alpha$-CuSCN and (2) a new bimetallic CZT structure. The solid-state reaction occurs at the more labile S-coordination sites, and the resulting products show melting behavior and glass transition. Both structures are ambient-stable and comprise mixed-valence metal cations, $\mathrm{Cu}^{\prime}$ and $\mathrm{Zn}^{\prime \prime}$. With respect to CuSCN, $E_{\mathrm{g}}^{\text {opt }}$ widens, VBM deepens, and $E_{\mathrm{F}}$ shifts away from VBM with the increasing amount of $\mathrm{Zn}$. DFT calculations reveal that $\alpha$-CuSCN containing $\mathrm{Zn}_{\mathrm{Cu}}^{+}$features electronic states of metals at both the VBM and CBM from $\mathrm{Cu} 3 d$ and $\mathrm{Zn} 4 s$, respectively. This work also demonstrates that CuSCN can be made melt-processable by mixing with $\mathrm{Zn}(\mathrm{SCN})_{2}$ and that the optical and electronic properties of CuSCN can be systematically tuned by adjusting the proportion of $\mathrm{Zn}$ in the structure.

\section{Author contributions}

CRediT descriptions. Chayanit Wechwithayakhlung: Methodology, Investigation, Data curation, Formal analysis, Visualization, and Writing - original draft. Suttipong 
Wannapaiboon: Methodology, Formal analysis, Validation, and Writing - review \& editing (XANES and EXAFS experiments). Sutassana Na-Phattalung: Methodology, Supervision, Validation, and Writing - review \& editing (DFT calculations). Phisut Narabadeesuphakorn, Similan Tanjindaprateep, and Saran Waiprasoet: Investigation (XANES and EXAFS experiments). Satoshi Horike: Conceptualization, Funding acquisition, Resources, Supervision, and Writing - review \& editing. Pichaya Pattanasattayavong: Conceptualization, Funding acquisition, Resources, Project administration, Supervision, Validation, Visualization, and Writing - review \& editing.

\section{Conflicts of interest}

There are no conflicts of interest to declare.

\section{Acknowledgements}

This research was supported by grant TRG6280013 jointly funded by Thailand's Synchrotron Light Research Institute (SLRI) and Thailand Research Fund (TRF) and grant FRB640087 funded by Thailand Science Research and Innovation (TSRI). C.W. and P.P. acknowledge Vidyasirimedhi Institute of Science and Technology for financial support. C.W., S.H. and P.P. also acknowledge funding from iCeMS-VISTEC Smart Materials Research Center. S.N. was supported by Thailand Science Research and Innovation Fund, contract number WUFF64101. Synchrotron Light Research Institute, Thailand, is also acknowledged for the provision of XAS beamtime at the Beamline 1.1W (Multiple X-ray Techniques, MXT). The authors also thank Dr. Daniel Packwood from iCeMS, Kyoto University, for valuable advice and computational resources. 


\section{References}

1 A. H. Norbury, Adv. Inorg. Chem. Radiochem., 1975, 17, 231-386.

2 J. Burmeister, Coord. Chem. Rev., 1990, 105, 77-133.

3 M. Kabešová, R. Boča, M. Melník, D. Valigura and M. Dunaj-Jurčo, Coord. Chem. Rev., 1995, 140, 115-135.

$4 \quad$ M. K. Nazeeruddin, A. Kay, I. Rodicio, R. Humphry-Baker, E. Mueller, P. Liska, N. Vlachopoulos and M. Graetzel, J. Am. Chem. Soc., 1993, 115, 6382-6390.

$5 \quad$ M. K. Nazeeruddin, P. Péchy and M. Grätzel, Chem. Commun., 1997, 1, 1705-1706.

6 M. K. Nazeeruddin, P. Péchy, T. Renouard, S. M. Zakeeruddin, R. Humphry-Baker, P. Comte, P. Liska, L. Cevey, E. Costa, V. Shklover, L. Spiccia, G. B. Deacon, C. A. Bignozzi and M. Grätzel, J. Am. Chem. Soc., 2001, 123, 1613-1624.

7 M. K. Nazeeruddin, S. M. Zakeeruddin, R. Humphry-Baker, M. Jirousek, P. Liska, N. Vlachopoulos, V. Shklover, C.-H. Fischer and M. Grätzel, Inorg. Chem., 1999, 38, $6298-6305$.

8 P. Pattanasattayavong, N. Yaacobi-Gross, K. Zhao, G. O. N. Ndjawa, J. Li, F. Yan, B. C. O'Regan, A. Amassian and T. D. Anthopoulos, Adv. Mater., 2013, 25, 1504-1509.

9 P. Worakajit, F. Hamada, D. Sahu, P. Kidkhunthod, T. Sudyoadsuk, V. Promarak, D. J. Harding, D. M. Packwood, A. Saeki and P. Pattanasattayavong, Adv. Funct. Mater., 2020, 30, 2002355.

10 A. Perumal, H. Faber, N. Yaacobi-Gross, P. Pattanasattayavong, C. Burgess, S. Jha, M. A. McLachlan, P. N. Stavrinou, T. D. Anthopoulos and D. D. C. Bradley, Adv. Mater., 2015, 27, 93-100.

11 L. Xu, Y. Li, L. Chen, J. Wang, C. Zheng, Y. Qi, R. Chen and W. Huang, ACS Sustain. Chem. Eng., 2018, 6, 17178-17183. 
K. Tennakone, K. P. Hewaparakkrama, M. Dewasurendra, A. H. Jayatissa and L. K. Weerasena, Semicond. Sci. Technol., 1988, 3, 382-387.

13 B. O'Regan and D. T. Schwartz, Chem. Mater., 1995, 7, 1349-1354.

14 K. Tennakone, G. R. R. A. Kumara, I. R. M. Kottegoda, V. P. S. Perera and G. M. L. P. Aponsu, J. Phys. D: Appl. Phys., 1998, 31, 2326-2330.

15 C. Lévy-Clément, R. Tena-Zaera, M. a. Ryan, A. Katty and G. Hodes, Adv. Mater., 2005, 17, 1512-1515.

16 G. Larramona, C. Choné, A. Jacob, D. Sakakura, B. Delatouche, D. Péré, X. Cieren, M. Nagino and R. Bayón, Chem. Mater., 2006, 18, 1688-1696.

17 J. Briscoe, D. E. Gallardo, S. Hatch, V. Lesnyak, N. Gaponik and S. Dunn, J. Mater. Chem., 2011, 21, 2517.

18 N. Yaacobi-Gross, N. D. Treat, P. Pattanasattayavong, H. Faber, A. K. Perumal, N. Stingelin, D. D. C. Bradley, P. N. Stavrinou, M. Heeney and T. D. Anthopoulos, Adv. Energy Mater., 2015, 5, 1401529.

19 M. Li, K. Gao, X. Wan, Q. Zhang, B. Kan, R. Xia, F. Liu, X. Yang, H. Feng, W. Ni, Y. Wang, J. Peng, H. Zhang, Z. Liang, H.-L. Yip, X. Peng, Y. Cao and Y. Chen, Nat. Photonics, 2017, 11, 85-90.

20 P. Qin, S. Tanaka, S. Ito, N. Tetreault, K. Manabe, H. Nishino, M. K. Nazeeruddin and M. Grätzel, Nat. Commun., 2014, 5, 3834.

21 S. Ye, W. Sun, Y. Li, W. Yan, H. Peng, Z. Bian, Z. Liu and C. Huang, Nano Lett., $2015,15,3723-3728$.

22 N. Wijeyasinghe, A. Regoutz, F. Eisner, T. Du, L. Tsetseris, Y.-H. Lin, H. Faber, P. Pattanasattayavong, J. Li, F. Yan, M. A. McLachlan, D. J. Payne, M. Heeney and T. D. Anthopoulos, Adv. Funct. Mater., 2017, 27, 1701818. 
23 N. Arora, M. I. Dar, A. Hinderhofer, N. Pellet, F. Schreiber, S. M. Zakeeruddin and M. Grätzel, Science, 2017, 358, 768-771.

24 J. E. Jaffe, T. C. Kaspar, T. C. Droubay, T. Varga, M. E. Bowden and G. J. Exarhos, J. Phys. Chem. C, 2010, 114, 9111-9117.

25 L. Tsetseris, J. Phys.: Condens. Matter, 2016, 28, 295801.

26 B. J. Holliday and T. M. Swager, Chem. Commun., 2005, 23.

27 L. Sun, T. Miyakai, S. Seki and M. Dincă, J. Am. Chem. Soc., 2013, 135, 8185-8188.

28 J. Xie, L. Wang and J. S. Anderson, Chem. Sci., 2020, 11, 8350-8372.

29 C. Wechwithayakhlung, D. M. Packwood, J. Chaopaknam, P. Worakajit, S. Ittisanronnachai, N. Chanlek, V. Promarak, K. Kongpatpanich, D. J. Harding and P. Pattanasattayavong, J. Mater. Chem. C, 2019, 7, 3452-3462.

30 J. Chaopaknam, C. Wechwithayakhlung, H. Nakajima, T. Lertvanithphol, M. Horpratum, T. Sudyoadsuk, V. Promarak, A. Saeki and P. Pattanasattayavong, 2021, $\operatorname{arXiv:2105.01024.~}$

31 A. Seitkhan, M. Neophytou, M. Kirkus, E. Abou-Hamad, M. N. Hedhili, E. Yengel, Y. Firdaus, H. Faber, Y. Lin, L. Tsetseris, I. McCulloch and T. D. Anthopoulos, Adv. Funct. Mater., 2019, 29, 1905810.

32 T. C. Narayan, T. Miyakai, S. Seki and M. Dincă, J. Am. Chem. Soc., 2012, 134, $12932-12935$.

33 M. E. Ziebel, L. E. Darago and J. R. Long, J. Am. Chem. Soc., 2018, 140, 3040-3051.

34 L. S. Xie, G. Skorupskii and M. Dincă, Chem. Rev., 2020, 120, 8536-8580.

35 G. Wu, J. Huang, Y. Zang, J. He and G. Xu, J. Am. Chem. Soc., 2017, 139, 13601363. 

S.-H. Han, ACS Appl. Mater. Interfaces, 2017, 9, 12930-12935. H. Arora, R. Dong, T. Venanzi, J. Zscharschuch, H. Schneider, M. Helm, X. Feng, E. Cánovas and A. Erbe, Adv. Mater., 2020, 32, 1907063.

H. Liu, Y. Wang, Z. Qin, D. Liu, H. Xu, H. Dong and W. Hu, J. Phys. Chem. Lett., $2021,12,1612-1630$.

C. Wechwithayakhlung, D. M. Packwood, D. J. Harding and P. Pattanasattayavong, J. Phys. Chem. Solids, 2021, 154, 110085.

41 K. Nomura, H. Ohta, A. Takagi, T. Kamiya, M. Hirano and H. Hosono, Nature, 2004, 432, 488-492.

K. Nomura, T. Kamiya, H. Ohta, K. Ueda, M. Hirano and H. Hosono, Appl. Phys. Lett., 2004, 85, 1993-1995.

43 A. Liu, H. Zhu, W.-T. Park, S.-J. Kang, Y. Xu, M.-G. Kim and Y.-Y. Noh, Adv. Mater., 2018, 30, 1802379.

44 A. Liu, H. Zhu, W.-T. Park, S.-J. Kim, H. Kim, M.-G. Kim and Y.-Y. Noh, Nat. Commun., 2020, 11, 4309. Lu and W. Lu, Appl. Phys. Lett., 2012, 100, 263502.

P. K. Nayak, J. A. Caraveo-Frescas, Z. Wang, M. N. Hedhili, Q. X. Wang and H. N. Alshareef, Sci. Rep., 2015, 4, 4672. Adv. Mater. Interfaces, 2015, 2, 1500374. 
K.-P. Xie, W.-J. Xu, C.-T. He, B. Huang, Z.-Y. Du, Y.-J. Su, W.-X. Zhang and X.-M. Chen, CrystEngComm, 2016, 18, 4495-4498.

50 M. J. Cliffe, E. N. Keyzer, M. T. Dunstan, S. Ahmad, M. F. L. De Volder, F. Deschler, A. J. Morris and C. P. Grey, Chem. Sci., 2019, 10, 793-801.

51 J. G. Bergman, J. H. McFee and G. R. Crane, Mater. Res. Bull., 1970, 5, 913-917.

52 X. Q. Wang, D. Xu, D. R. Yuan, Y. P. Tian, W. T. Yu, S. Y. Sun, Z. H. Yang, Q. Fang, M. K. Lu, Y. X. Yan, F. Q. Meng, S. Y. Guo, G. H. Zhang and M. H. Jiang, Mater. Res. Bull., 1999, 34, 2003-2011.

53 X.-Q. Wang, D. Xu, M.-K. Lü, D.-R. Yuan, G.-H. Zhang, F.-Q. Meng, S.-Y. Guo and M. Zhou, Cryst. Res. Technol., 2001, 36, 73-84.

54 X. Q. Wang, D. Xu, M. K. Lu, D. R. Yuan, J. Huang, G. W. Lu, G. H. Zhang, S. Y. Guo, H. X. Ning, X. L. Duan, Y. Chen and Y. Q. Zhou, Opt. Mater., 2003, 23, 335341.

55 J.-L. Do and T. Friščić, ACS Cent. Sci., 2017, 3, 13-19.

56 D. Umeyama, S. Horike, M. Inukai, T. Itakura and S. Kitagawa, J. Am. Chem. Soc., $2015,137,864-870$.

57 T. D. Bennett and S. Horike, Nat. Rev. Mater., 2018, 3, 431-440.

58 S. Horike, S. S. Nagarkar, T. Ogawa and S. Kitagawa, Angew. Chem. Int. Ed. , 2020, $59,6652-6664$.

59 D. L. Smith and V. I. Saunders, Acta Cryst. B, 1981, 37, 1807-1812.

60 M. Kabešová, M. Dunaj-jurčo, M. Serator, J. Gažo and J. Garaj, Inorganica Chim. Acta, $1976,17,161-165$.

61 C. Raiß, K. Peppler, J. Janek and P. Adelhelm, Carbon, 2014, 79, 245-255. 
62 R. A. Bailey, S. L. Kozak, T. W. Michelsen and W. N. Mills, Coord. Chem. Rev., 1971, 6, 407-445.

63 M. Kabešová, J. Kohout and J. Gažo, Inorganica Chim. Acta, 1978, 31, L435-L436.

64 R. D. Shannon, Acta Cryst. A, 1976, 32, 751-767.

65 S. Zhang and J. Northrup, Phys. Rev. Lett., 1991, 67, 2339-2342.

66 J. E. Northrup and S. B. Zhang, Phys. Rev. B, 1994, 50, 4962-4964.

67 R. F. W. Bader, Atoms in molecules : a quantum theory, Oxford University Press, Oxford, 1990.

68 P. Pattanasattayavong, G. O. Ngongang Ndjawa, K. Zhao, K. W. Chou, N. YaacobiGross, B. C. O’Regan, A. Amassian and T. D. Anthopoulos, Chem. Commun., 2013, 49, 4154-4156.

69 S. S. Nagarkar, H. Kurasho, N. T. Duong, Y. Nishiyama, S. Kitagawa and S. Horike, Chem. Commun., 2019, 55, 5455-5458. 